E International

\title{
Select Legal Considerations for Shared Automated Driving
}

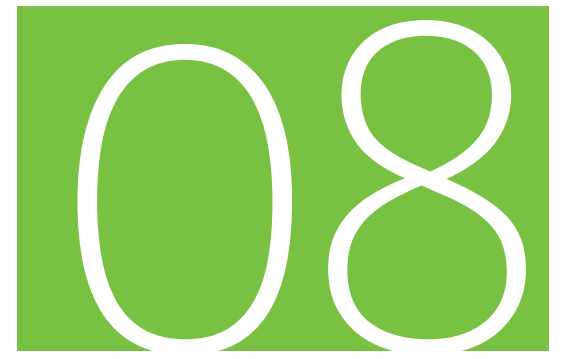

Discussion Paper 2017• 08

Bryant Walker

Smith

South Carolina Law

School, Coloumbia, USA 


\title{
EInternational Transport Forum
}

\section{Select Legal Considerations for Shared Automated Driving}

Discussion Paper No. 2017-08

Prepared for the Roundtable on

Cooperative Mobility Systems and Automated Driving

(6-7 December 2016)

\author{
Bryant Walker Smith \\ South Carolina Law School, Coloumbia, USA
}

July 2017 


\title{
The International Transport Forum
}

The International Transport Forum is an intergovernmental organisation with 59 member countries. It acts as a think tank for transport policy and organises the Annual Summit of transport ministers. ITF is the only global body that covers all transport modes. The ITF is politically autonomous and administratively integrated with the OECD.

The ITF works for transport policies that improve peoples' lives. Our mission is to foster a deeper understanding of the role of transport in economic growth, environmental sustainability and social inclusion and to raise the public profile of transport policy.

The ITF organises global dialogue for better transport. We act as a platform for discussion and prenegotiation of policy issues across all transport modes. We analyse trends, share knowledge and promote exchange among transport decision-makers and civil society. The ITF's Annual Summit is the world's largest gathering of transport ministers and the leading global platform for dialogue on transport policy.

The Members of the Forum are: Albania, Armenia, Argentina, Australia, Austria, Azerbaijan, Belarus, Belgium, Bosnia and Herzegovina, Bulgaria, Canada, Chile, China (People's Republic of), Croatia, Czech Republic, Denmark, Estonia, Finland, France, Former Yugoslav Republic of Macedonia, Georgia, Germany, Greece, Hungary, Iceland, India, Ireland, Israel, Italy, Japan, Kazakhstan, Korea, Latvia, Liechtenstein, Lithuania, Luxembourg, Malta, Mexico, Republic of Moldova, Montenegro, Morocco, the Netherlands, New Zealand, Norway, Poland, Portugal, Romania, Russian Federation, Serbia, Slovak Republic, Slovenia, Spain, Sweden, Switzerland, Turkey, Ukraine, the United Arab Emirates, the United Kingdom and the United States.

\author{
International Transport Forum \\ 2 rue André Pascal \\ F-75775 Paris Cedex 16 \\ contact@itf-oecd.org \\ www.itf-oecd.org
}

\section{ITF Discussion Papers}

ITF Discussion Papers make economic research, commissioned or carried out in-house at ITF, available to researchers and practitioners. They describe preliminary results or research in progress by the author(s) and are published to stimulate discussion on a broad range of issues on which the ITF works. Any findings, interpretations and conclusions expressed herein are those of the authors and do not necessarily reflect the views of the International Transport Forum or the OECD. Neither the OECD, ITF nor the authors guarantee the accuracy of any data or other information contained in this publication and accept no responsibility whatsoever for any consequence of their use. This document and any map included herein are without prejudice to the status of or sovereignty over any territory, to the delimitation of international frontiers and boundaries and to the name of any territory, city or area. Comments on Discussion Papers are welcome. 


\section{Table of Contents}

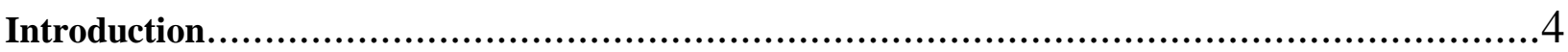

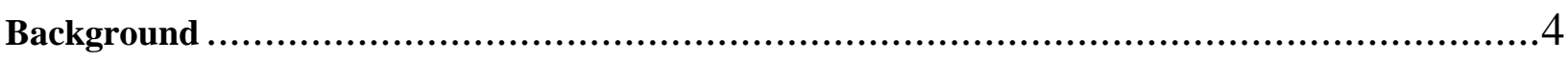

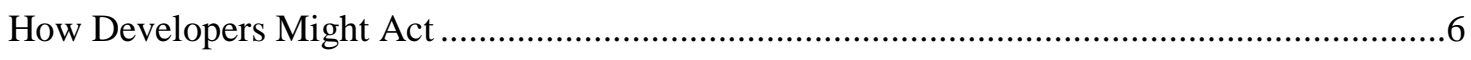

How Governments Might Act.......................................................................................6

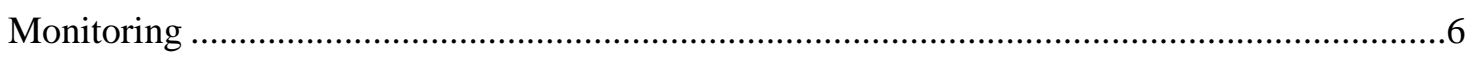

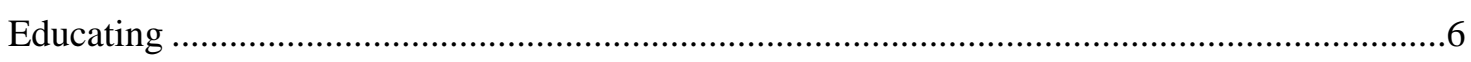

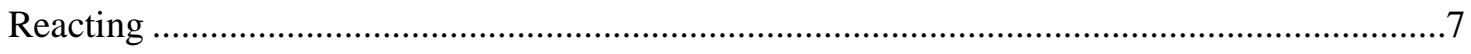

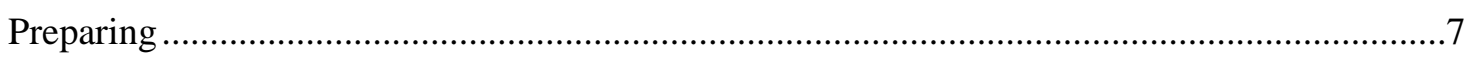

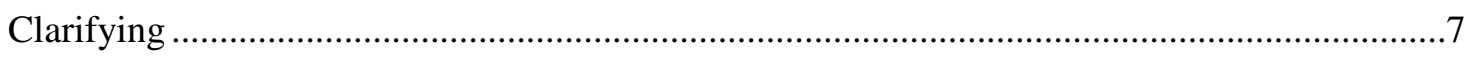

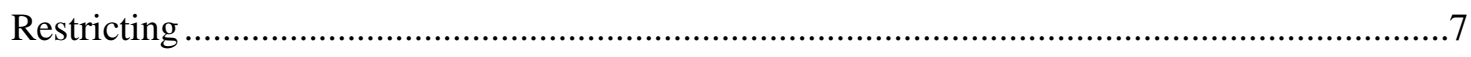

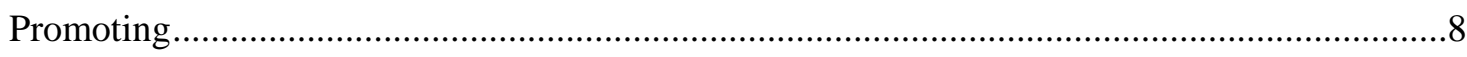

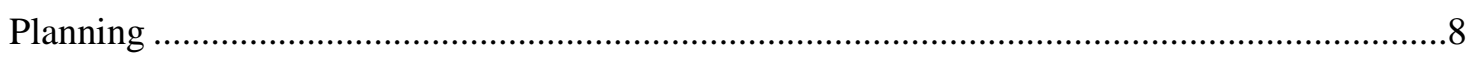

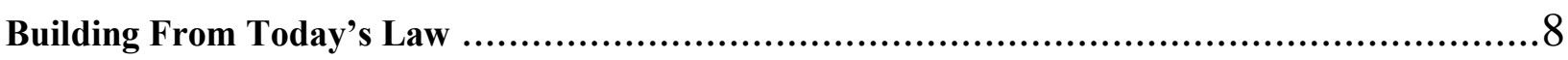

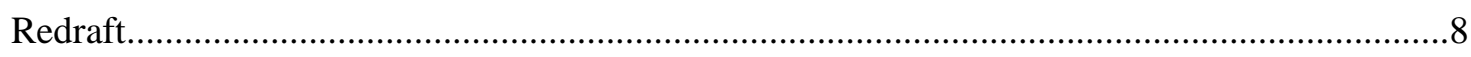

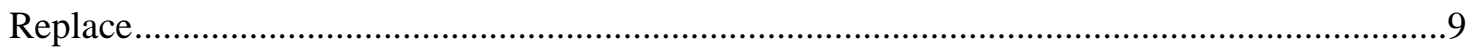

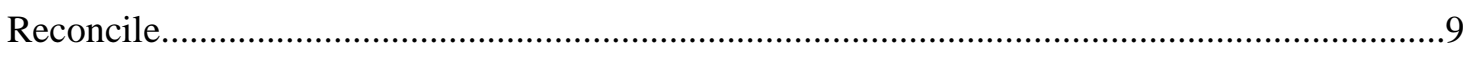

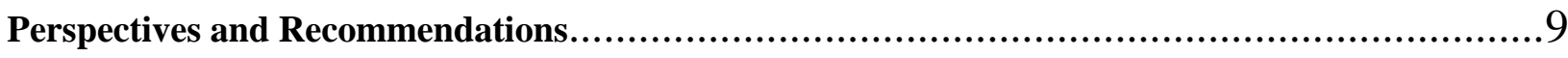

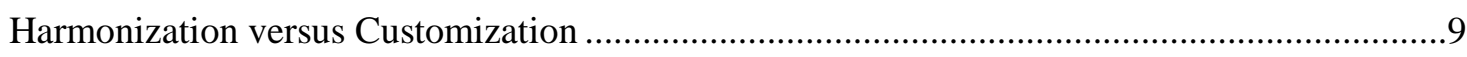

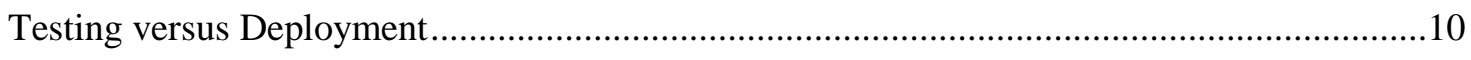

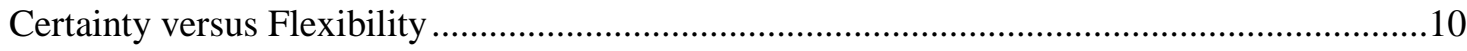

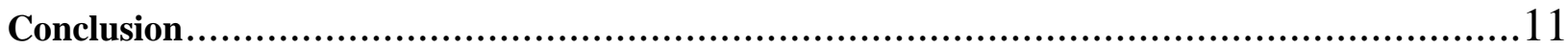




\section{Introduction}

This discussion paper introduces several legal considerations for shared automated driving with a view toward grounding a broader policy discussion. It begins by discussing likely implementations of shared automated driving. It next considers the kinds of legal actions that developers and regulators of these automated driving systems might take to promote or police them. It then connects these potential actions to existing law by describing three ways of adapting that law to automated driving. Finally, it provides specific perspectives and recommendations on this and any legal change.

\section{Background}

Automated driving encompasses a diverse set of actual and potential technologies, applications, and business cases. A small subset of these - in particular, a fleet of truly driverless vehicles ${ }^{1}$ accessible to the public - is most closely aligned with the vision of the ITF roundtable for which this paper was prepared. I have previously described these so-called robotaxis as one of three pathways to fully automated driving. ${ }^{2}$ Others have analysed how these vehicles might replace individually owned cars and how they could complement or challenge conventional mass transit.

Implementations other than robotaxis are also relevant to shared automation. Driving automation systems that merely assist the human driver could make conventional mass transit safer and more efficient in the near term. Delivery robots that carry goods rather than people could nonetheless eliminate some human trips altogether. The current model of individual vehicle ownership may even facilitate both sharing and automation - at least according to Tesla.

In contrast to the applications and business cases for shared automation, there is at least an emerging consensus on categorizing the underlying technologies. SAE International's Taxonomy and Definitions for Terms Related to Driving Automation Systems for On-Road Motor Vehicles (J3016), which is now freely available, reflects and reinforces this consensus. ${ }^{3}$ The levels of automation are the most famous part of this taxonomy, and they are dutifully reproduced below: 


\begin{tabular}{|c|c|c|c|c|c|c|}
\hline \multirow[b]{2}{*}{ ฮ } & \multirow[b]{2}{*}{ Name } & \multirow[b]{2}{*}{ Narrative definition } & \multicolumn{2}{|c|}{$D D T$} & \multirow[b]{2}{*}{$\begin{array}{c}D D T \\
\text { fallback }\end{array}$} & \multirow[b]{2}{*}{$O D D$} \\
\hline & & & $\begin{array}{c}\text { Sustained } \\
\text { lateral and } \\
\text { longitudinal } \\
\text { vehicle motion } \\
\text { control }\end{array}$ & OEDR & & \\
\hline \multicolumn{7}{|c|}{ Driver performs part or all of the $D D T$} \\
\hline 0 & $\begin{array}{l}\text { No Driving } \\
\text { Automation }\end{array}$ & $\begin{array}{l}\text { The performance by the driver of the entire } D D T \text {, even } \\
\text { when enhanced by active safety systems. }\end{array}$ & Driver & Driver & Driver & $\mathrm{n} / \mathrm{a}$ \\
\hline 1 & $\begin{array}{c}\text { Driver } \\
\text { Assistance }\end{array}$ & $\begin{array}{l}\text { The sustained and } O D D \text {-specific execution by a } \\
\text { driving automation system of either the lateral or the } \\
\text { longitudinal vehicle motion control subtask of the DDT } \\
\text { (but not both simultaneously) with the expectation that } \\
\text { the driver performs the remainder of the DDT. }\end{array}$ & $\begin{array}{l}\text { Driver and } \\
\text { System }\end{array}$ & Driver & Driver & Limited \\
\hline 2 & $\begin{array}{c}\text { Partial } \\
\text { Driving } \\
\text { Automation }\end{array}$ & $\begin{array}{l}\text { The sustained and } O D D \text {-specific execution by a driving } \\
\text { automation system of both the lateral and longitudinal } \\
\text { vehicle motion control subtasks of the } D D T \text { with the } \\
\text { expectation that the driver completes the OEDR } \\
\text { subtask and supervises the driving automation system. }\end{array}$ & System & Driver & Driver & Limited \\
\hline \multicolumn{3}{|c|}{ ADS ("System") performs the entire DDT (while engaged) } & & & & \\
\hline 3 & $\begin{array}{l}\text { Conditional } \\
\text { Driving } \\
\text { Automation }\end{array}$ & $\begin{array}{l}\text { The sustained and ODD-specific performance by an } \\
A D S \text { of the entire DDT with the expectation that the } \\
D D T \text { fallback-ready user is receptive to ADS-issued } \\
\text { requests to intervene, as well as to DDT performance- } \\
\text { relevant system failures in other vehicle systems, and } \\
\text { will respond appropriately. }\end{array}$ & System & System & $\begin{array}{l}\text { ready user } \\
\text { (becomes } \\
\text { the driver } \\
\text { during } \\
\text { fallback) }\end{array}$ & Limited \\
\hline 4 & $\begin{array}{c}\text { High } \\
\text { Driving } \\
\text { Automation }\end{array}$ & $\begin{array}{c}\text { The sustained and } O D D \text {-specific performance by an } \\
A D S \text { of the entire } D D T \text { and } D D T \text { fallback without any } \\
\text { expectation that a user will respond to a request to } \\
\text { intervene. }\end{array}$ & System & System & System & Limited \\
\hline 5 & $\begin{array}{c}\text { Full } \\
\text { Driving } \\
\text { Automation }\end{array}$ & $\begin{array}{l}\text { The sustained and unconditional (i.e., not } O D D \text { - } \\
\text { specific) performance by an } A D S \text { of the entire } D D T \\
\text { and } D D T \text { fallback without any expectation that a user } \\
\text { will respond to a request to intervene. }\end{array}$ & System & System & System & Unlimited \\
\hline
\end{tabular}

These levels are initially useful for dispelling misconceptions about automated driving. Unfortunately, the vexing if understandable combination of secrecy and self-promotion within the private sector has contributed to widespread confusion about the current state of automated driving technologies and even the extent of their deployment. In particular, automated driving on public roads without realtime human supervision will represent a massive leap from the kinds of testing that predominate today. This gulf between level two and level four - and the challenges inherent in each level - are often lost in misleading reports that a company is testing "driverless" vehicles somewhere in the world.

Much of the discussion of and innovation in shared automation will likely focus on level four, in which an automated driving system performs all of the real-time driving tasks under specified conditions. These specified conditions are the system's operational design domain (ODD), a concept that is overshadowed by but at least as important as the level of automation. For technical, legal, economic, and prudential reasons, early shared automation systems may be limited to specific roads in specific communities. 
The details of each particular implementation, including the location, will affect the legal analysis. A governmental operator, a commercial operator, and an individual who makes her vehicle available for sharing could face different legal obligations and liabilities, including with respect to licensing, the accommodation of disabled users, and other compliance issues. In the early days of the automobile, courts and legislatures in the United States addressed whether the legal operator of a vehicle was its chauffeur or its owner-occupier; automation may similarly raise the question of when the user of an automation system has no greater responsibilities than an ordinary passenger.

Legal and political battles over services like UberX and Lyft, including the invention of the term "transportation network company" to describe them, show both that details matter and that these details are malleable. Existing rules for taxi dispatchers and drivers could and probably did apply to these services. Calling them something else, however, created the conceptual foundation for regulating them differently — and, in many cases, more permissibly.

\section{How developers might act}

Transportation network companies are a useful case study because they suggest the range of approaches that a given developer of a shared automation system may take toward existing law. In general, such a developer has an incentive to understand that law, to determine whether any changes are necessary or otherwise desirable, and to advocate for those changes.

However, developers may tolerate legal uncertainty to varying degrees. Some developers, especially established companies with political influence, may want to quickly craft and codify a clear legislative framework that supports their vision even to the exclusion of competing visions. Other developers, especially obscure startups, may be more comfortable operating with some legal uncertainty in their early activities. And still others, especially aggressive companies eager to court the market, may prefer to create facts on the ground that encourage eventual legal ratification.

\section{How governments might act}

Whether independently or in connection with these private actors, governments will also decide whether and if so how to act with respect to automated driving. This action can include monitoring, educating, reacting, preparing, clarifying, restricting, promoting, and planning. Briefly consider each of these potential actions in turn without regard for their desirability:

\section{Monitoring}

Accurate information about automated driving is a predicate to effective regulation. Governments can collect this information informally (through consultations and connections) or formally (through requests for information, investigations, and reporting requirements). As automated driving is introduced onto public roads, systematic monitoring may be especially important so that specific technologies can be efficiently linked to specific incidents. This monitoring could involve, for example, incorporating automation information into vehicle databases and collecting data about crashes in a consistent manner.

\section{Educating}

As governments educate themselves on automated driving, they may also educate the general public on the risks and opportunities of these technologies. Public perception will affect whether technologies are used correctly, whether applications are accepted, and whether business cases are embraced. A misinformed public may expect too much or too little from the technologies and may prove fickle in the aftermath of a serious crash or other incident. These perceptions in turn can expand or restrict the 
flexibility available to public actors. For example, governments may be more willing to adopt a broadly permissive interpretation of the Conventions on Road Traffic if the public is broadly supportive of automated driving.

\section{Reacting}

The administrative functions of government will inevitably and repeatedly face automated driving. The national vehicle authority of an EU member state may be asked to grant type approval for a vehicle that incorporates an automated driving system, or Transport Canada may be asked to grant an exemption to a particular national vehicle safety standard. The US National Highway Traffic Safety Administration may receive reports of potential defects in an automated driving system. Local police may respond to a crash involving an automated driving system. A court may eventually hear a civil or criminal case involving that crash. The instances that actually occur will likely come faster-and demand a faster response - than many might expect. In many cases, for example, governments decided how existing law applied to Uber's business model only after the company had already established itself on the ground.

\section{Preparing}

In anticipation of these situations, governments can prepare to react. Developing and communicating a break-the-glass plan that details how an agency will respond to a serious automated driving crash is a concrete example of this preparation. More abstractly, governments may also ensure that agencies have sufficient resources, expertise, and authority to react appropriately to relevant automated driving developments. The US Department of Transportation's recent review of its existing and potential regulatory tools is an important step in this direction.

\section{Clarifying}

The current legal status of automated driving, including specific technologies and applications, is arguably unclear. My 2012 review of relevant law (including the Conventions on Road Traffic) noted various legal provisions that, depending on their construction, could be consistent or inconsistent with some forms of automated driving.4 More recently, the US Department of Transportation identified additional provisions within the federal motor vehicle safety standards that may or may not conflict with specific implementations of automated driving. ${ }^{5}$ The lack of authoritative interpretation provides flexibility but also uncertainty: Developers and regulators have more space for technical, business, and even regulatory innovation, but legal assumptions could be upended long after decisions have been made on the basis of them.

\section{Restricting}

Restricting an activity by conditioning its legality is regulation in the narrowest sense. In general, these restrictions may be necessary to check market failures that threaten key interests, including individual autonomy or safety and societal efficiency. Legislatures, administrative agencies, and courts can all have a restrictive effect, as can private actors such as industry (by developing standards), insurers (by setting conditions of insurance), certifiers (by setting conditions of certification), and litigants (by shifting economic costs). Restrictions can be imposed at various levels of government (including international, national, subnational, or local) and times (including before development, before deployment, after deployment, or after market saturation). Restrictions might apply to a variety of legal persons, including developers, producers, modifiers, owners, users, operators, insurers, and certifiers, and to a variety of activities, including design, testing, deployment, production, sale, modification, 
registration, insurance, deployment, use, maintenance, recall, and disposal. These lists, which are far from comprehensive, illustrate the complexity and diversity of restrictive regulation.

\section{Promoting}

Governments may also promote automated driving even as they restrict it. A recent article describes nearly fifty strategies with which governments at all levels can encourage the development and deployment of automated driving. ${ }^{6}$ These strategies, some of which overlap with other governmental actions discussed in this section, include identifying a point person for automated driving, conducting a legal audit to identify potential complications under existing law, internalizing the costs of driving and parking, embracing regulatory flexibility, and developing a clear horizontal and vertical network of support, among many others. At the heart of the article is a call to expect more not only from automated driving systems but also from today's drivers in today's vehicles.

\section{Planning}

Planning is broader than preparing in scope, timing, and ambition. It seeks to understand how technologies can be used to advance larger social goals. As I wrote previously:

Planning of this kind is one of the most important contributions that governments can make to automated driving in the long term. The status quo is far from perfect. Automated driving may address some of today's problems while exacerbating others. Similarly, automated driving may be advantaged by some of those problems but disadvantaged by others. Understanding these issues - which may not necessarily be a priority for the companies developing and deploying relevant technologies—will help governments determine the role that automated driving can play in advancing larger public policy goals.7

\section{Building from today's law}

As the discussion above suggests, a range of legal changes and actions are possible. They may even be desirable - depending on the law, objectives, and legal philosophy of the particular jurisdiction as well as the applications, business model, and legal risk tolerance of the individual developers. Whether these actions apply, clarify, or modify existing law, they will necessarily engage with that law.

In this way, automated driving could implicate many of today's legal codes. These may include the Conventions on Road Traffic, international vehicle regulations, and (sub)national regimes for vehicle safety, vehicle registration, driver licensing, and traffic safety, and transport concessions, among many others. Many of these vary by country (or, in some cases, by federal state, province, or even municipality) in large or small ways.

Broadly, there are three potential approaches to dealing with one or more of these existing codes: redraft, replace, or reconcile.

\section{Redraft}

Redrafting a particular legal code would involve reviewing and changing relevant provisions so that every one of those provisions applied with equal clarity to both conventional and automated driving. 
Vehicle standards, for example, would simultaneously and specifically address vehicles with as well as without conventional steering wheels and foot brakes. This redrafting exercise would be massive but would also provide a unique opportunity to harmonize law across jurisdictions for conventional as well as automated driving.

\section{Replace}

Rather than redraft a particular legal code, a government might categorically exempt automated driving from the code and then start from scratch to develop a new regime applicable only to this form of driving. Laws regulating the transportation network companies discussed above are a more limited example of this approach: They supplant existing taxi regulations in favor of a specialized set of rules applicable only to these TNCs. Replacing a potentially anachronistic regime with one that is more targeted may be cleaner and simpler than redrafting the entire code but may also introduce boundary problems when the line between automated and conventional driving is not entirely clear. This, however, is less of a concern for the truly driverless vehicles that are likely to be the foundation for shared automation.

\section{Reconcile}

A hybrid approach that falls somewhere between redrafting and replacing, reconciling would use definitions, interpretive guidance, clarifications, and regulatory mechanisms to map existing law onto automated driving. In the United States, some states have started down this path by, for example, specifying the driver of a vehicle when its automated driving system is engaged. Unfortunately, these initial efforts to tackle the vehicle code will likely raise far more questions than they answer. In particular, somewhat arbitrarily assigning the label of "driver" to a person who may not be present or able to drive conventionally could confuse other obligations and liabilities.

A more thorough — but still far from perfect - example of reconciling a state's vehicle code with automated driving is the model language from my 2012 analysis. ${ }^{8}$ This text also accepts the emphasis on drivers that is typical of vehicle codes. However, in language that is far too convoluted, it expands the definition of driver to include nonhuman entity that had developed the automated driving system. In this way, it places obligations of compliance on that developer. Rules of interpretation then address the many absurdities that would otherwise result from this expansion.

\section{Perspectives and recommendations}

This section builds on the previous discussion in several specific areas: harmonization versus customization, testing versus deployment, and certainty versus flexibility.

\section{Harmonization versus customization}

As a general matter, harmonization and even standardization are largely-though not entirelybeneficial. For early applications, however, it is probably not necessary. Moreover, the delay and uncertainty inherent in a massive international harmonization effort could actually impede some local deployments. As I wrote previously: 
Uniformity across jurisdictions may be desirable for mass-produced vehicles, while tailored regimes may support pilots, demonstrations, and local deployments. Rather than focusing on developing a uniform automated driving law, governments could cooperate on standardizing or harmonizing more of their underlying legal frameworks - particularly those that govern vehicles, drivers, driving, insurance, dealerships and commercial vehicle operations.

Governments can also promote harmonization through principles of comity and reciprocity. Smaller jurisdictions unwilling or unable to devote resources to a regulatory regime for automated driving might simply defer to the regulatory determinations of other jurisdictions. While it is not free of friction, the European Union's homologation regime provides a useful model for a stronger form of reciprocity.

\section{Testing versus deployment}

Any line drawn between testing and deployment will become increasingly arbitrary and unclear. However, tests - as well as field operational tests, pilots, beta projects, and demonstrations, among others - are simply terms that are used functionally.

These terms may be used to signal that an automated driving system is not fully "ready." But even a test vehicle should be operated as part of a broader system - perhaps involving some form of human supervision - that is appropriate for the task at hand. Moreover, a long history of automotive recalls suggests that not even production vehicles are always fully ready, and the gradual embrace of over-theair updates will further blur whatever theoretical bright line existed between production systems and everything else.

These terms may also or alternately be used to avoid impractical legal requirements and restrictions that apply only to production vehicles. If so, then the better approach is to move from fiction to function by determining what conditions should apply to a particular activity. Under this approach, the risk of a particular activity matters more than its binary classification.

\section{Certainty versus flexibility}

As noted above, there is tension in law between certainty and flexibility. Legal regimes for automated driving — and shared automation in particular - should be attentive to both objectives.

Jurisdictions should act with more clarity in specifying who is and is not the driver of a vehicle in other words, the natural or legal person to whom a wide assortment of legal obligations and liabilities at least presumptively apply. Although some states in the United States have now affirmatively (if, as discussed, unsatisfying) defined the driver, no state has expressly indicated who is not a driver. This matters for shared automation systems that may be used by passengers who lack either a connection to the vehicle or an ability to drive.

At the same time, jurisdictions should provide more flexibility for both technical and regulatory innovation. This is the driving motivation for the "public safety case" that I have previously advocated. ${ }^{10}$ Rather than directing developers to comply with specific requirements that regulators could not realistically create and maintain, the public safety case invites these developers to share their safety philosophies with those regulators and the public that they serve. In order to obtain an approval or an exemption — or simply to avoid enhanced regulatory scrutiny - these developers would provide evidence of what they are doing and why they believe it to be reasonably safe. These submissions would in turn be evaluated not for their correctness but instead for their reasonableness. 


\section{Conclusion}

Unlike math, law varies dramatically across both time and space. This variation complicates both analysis of and, ultimately, compliance with that law. But this variety also provides room for technical and regulatory innovation. At least initially, localized deployments of shared automation may vary by location, particularly if different developers advocate for different regimes while governments embrace a more flexible model of regulation. The many technologies, applications, and business cases that make up automated driving are rapidly evolving in ways that will allow for customization, comparison, and competition. The governments that are building tomorrow's law on the foundation of today's can do the same. 


\section{Notes}

SAE J3016 uses the term "automated driving system-dedicated vehicle" or "ADS-DV."

2 How Governments Can Promote Automated Driving, newlypossible.org.

3 SAE J3016, http://standards.sae.org/j3016_201609.

$4 \quad$ Automated Vehicles Are Probably Legal in the United States, newlypossible.org.

$5 \quad$ Review of FMVSS for Automated Vehicles (Volpe Center), ntl.bts.gov/lib/57000/57000/57076/Review FMVSS AV Scan.pdf

How Governments Can Promote Automated Driving, newlypossible.org.

Id.

Automated Vehicles Are Probably Legal in the United States, newlypossible.org.

How Governments Can Promote Automated Driving, newlypossible.org.

10 Regulation and the Risk of Inaction, newlypossible.org; How Governments Can Promote Automated Driving, newlypossible.org; see also US Department of Transportation Automated Vehicles Policy, www.transportation.gov/AV (describing a 15-point safety assessment). 
